\title{
Some Albanian Socio-Cultural Problems in the Framework of the Theory of Linguistic Deficit
}

\author{
Dr. Edlira Troplini (Abdurahmani) \\ "Aleksander Moisiu" University, Durres- Albania \\ E-mail: edlira.troplini@yahoo.com
}

\section{Doi:10.5901/jesr.2013.v3n7p508}

\section{Abstract}

\begin{abstract}
After some research and observations of the role of external linguistic factors of natural character such as: age, sex, ethnic group, after several treatments of social character factors such as, level of education and new empiric observations of socioeconomic class, we have reached some conclusions about the area of linguistic prejudice, especially regarding the role of language in the learning performance of students. At the epicenter of this research is the theory of linguistic deficit. So we are supporting Bernstein's data, enriching them with the findings of his followers and detractors, even though we are convinced that Bernstein's works have been appropriate seeds of much discussions and subsequent achievements. (Klein 1977) For this reason, after these treatments we have opened new windows of studying which lead us on the grounds that linguistic deficit prevents not merely academic performance (or vice versa), but prevents the individual to be successful for the other sociocultural spheres (or vice versa). This is considered by Hudson as a lack of linguistic competence: closely linguistic inequality. It is on this basis that we consider to extend our thesis in this study, having as its object the Albanian linguistic community.
\end{abstract}

Keywords: sociolinguistics, language deficit, productivity, Albanian community.

Surveys and observations of the role of external language factors of natural character such as: age, sex, ethnic group, level of education, we have materialized through examples from the southern Albanian Dialect - Cham's dialect, within the interaction "standard language-dialect" . These observations were incentive for further sociolinguistic reviews (Troplini 2012).

Initially we took a test of reviews in the Albanian social community of external factors of social character, socioeconomic class (Troplini a, b, c, 2010), after which we came to some conclusions about our Albanian society and opened a new window of study on the factors detailed above, under the current theory of linguistic deficit, the role of language in learning performance of students, language planning, language prejudices etc.

In this flow moves the paper in question, which addresses a new topic in the field of sociolinguistic studies in Albania. In this paper are thrown some new ideas in the form of hypotheses, which later will be treated separately from us, through empirical research, through examples and details, arguments and counterarguments, believing that this work will be expanded in the future in the form of a monography.

Although sociolinguists have generally talked about external factors to language, we preferred list below some data collected by Berruto (1994: 97), according to which external factors of social and natural character are:

1. AGE. According Berruto young people speak differently from the elderly ones(...), young people are renovating and the elderly are preserving (...).

This is proven by sociolinguistic researches in Albania, which have been more or less dialectological following issues. Academician Shkurtaj initially makes a research on the dialect of the city of Lezha (Shkurtaj 1981) making a division of speakers by three generations: the older generation, middle generation and the younger generation. The researcher is thereby reviews initiator within the report of the new with the old, but also a mentor for young researchers in sociolinguistic reviews of the speech, precisely in this point of view.

2. Gender (SEX). Women speak differently from men, (...). Despite this claim, which we find on many sociolinguists Berruto said that (...) this is not proven, even there is evidence to the contrary proving that the majority of female sex-speaking tend to innovation. (...).

According Eqrem Çabej, the euphemism show a kind of differentiation of the dialect of women or womanly lecture (Shkurtaj 2009). However this great scholar has written to the Albanian early euphemism, when the dialect of women showed a clear differentiation from the type of men dialect.

From the research we have done this factor, I would add that, are precisely educated women, to a certain 
status, which, regardless of age, differ in their dialect precisely because they are more innovative than the rest of the uneducated women. Also, in Albania day by day is apparently progressing the trend to integrate the image of women everywhere in society. This has been the object of many foreign-funded training, which contribute more and more to leveling the gender gap, closing the deficit to carry social and cultural consequence of disengagement as well as women should have in different spheres of life .

3. Ethnic origin. The claim that ethnicity conditions manner of speech has nothing to do with racism (...), ultimately, - says Berruto, any difference of linguistic behavior that comes from the geographical origin is an ethnic difference (...).

If we analyze the situation of the Albanian dialects, will understand that Berruto really has fair. This can be proved quite easily if we examine the behavior of individual language speakers in all the Albanian dialects today, namely:

- In the early dialects of Albanian diaspora: Arbëresh dialect of Italy, Greece Arbëresh, Arbëresh of Zara ... etc;

- In the Albanian dialects within Albanian state before and after the 90-s. We recall the big change after years of democracy (after 90-s), which dominated the mechanical movements of populations from rural to urban areas and especially towards the center (Durres-Tirana - Elbasan).

- In a separate group mention the dialect of Albanian immigrants, who underwent the immigration process after 90s onwards.

- $\quad$ The dialect of Albanian ethnic territories (in Kosovo, Macedonia and Montenegro)

- In a separate group also highlight the province's southern dialect (the term used by Çabej) of Albanian language, the dialect of Cham, whose inhabitants after the '44-es were subjected to ethnic cleansing from their homes in Greece wandering in the form of a disheveled diaspora throughout Albanian state.

4. Social- Economic Class, according to the author deals with the differences between the linguistic behavior of the respective speakers of medium-high grade and corresponding low grade speakers. According to him, this difference is highly significant (...) In particular, -he says, - linguistic behavior seems quite closely related to the income which bring not only goods, but also cultural goods available to different types of socio-economic classes.

As claims the author, but as we will mention in the paper, the initiator of this issue has been Bernstein, who through his theory of linguistic deficit is the subject of a long discussion, paving the way for a series of sociolinguistic studies.

5. Education Level: according Berruto school education and intellectual capacity rate significantly penetrate to linguistic behavior, both interlocutors of the same sex, the same social class, if one is educated and the other not, the possibility exists that the linguistic behavior the first to be formed, richer...etc., than that of the latter especially, in terms of the selected registers.

As can be understood from the explanation of each of the factors, the interplay between them is inevitable, as regardless of a particular individual may or may not be educated, he may belong male or female sex, there may be some age, may belong to a certain social stratum and so on .... . So, all these ingredients combine and differ according to the case and what is most important is that all these factors create social differences of linguistic behavior.

As we shall see below, the linguistic diversity in the behavior of individuals is created not only due to the aforementioned factors as age, sex, ethnicity, class and level of education, but also due to social class, social group, status and role, include clear here, origin, race, religion, politics, intelligence, personality, who are valued variables in Sociolinguistics. Furthermore, should not overlook the fact that for one moment that diversity always created in accordance with the historical and cultural context, the situation, the development of each country, therefore the life of each of the speech.

All these factors give us the possibility of multiple treatments within the deficits they cause not just in teaching performance (from which was shaped the theory of linguistic deficit itself), but also in achieving social goods, values and virtues, in our job and relationships, in culture and anywhere etc.

Let us see how reflex the mentioned factors in Albanian social community. We are retaking once again in consideration ethnicity belonging.

As I mentioned above, the situation of the Albanian dialects is more or less this: the dialects within the state territory of Albania know more or less developing an orientation toward general Albanian. After the 90s, with the change of systems, mechanical movements of the population had an orientation from rural to urban areas, mainly towards the center (Tirana, Durres, Elbasan, etc., as developed areas of Albania). 
As in many countries, we can't even talk to the standard (conventionally created language, artificial language), without first talking to dialects, true and natural language of the nation (Troplini 2011). We have both existed and continues to exist a convergent relation between the so-called "official Albanian" and "regional dialect". But, on the other hand, can't claim that this kind of report do not accept development, as well as changes in each version of divergent terms.

Sociolinguists have fallen into the same opinion when they say that in the war of dialect words like to withdraw and leave the place opened to features of literary language or have a place to the latter (Gjinari 1985), wins the change and the orientation towards language with greater prestige as the official language standard (Shkurtaj 2003). On the other hand, should not be overlooked even Hudson's opinion that it carries with it the risk because leads to underestimate many of characteristic linguistic forms of his group ... "Children who leave the group local forms and make their own those forms that are accepted at the national level, do actually own forms that are symbols of identification of another group." (Hudson 2002: 234)

Without denying the quotes above, after a thorough study of the dialects to affirm that the above conclusions (about the report convergent / divergent) for "the prestige dialect" or so-called "family dialect" are substantially in line with life of each of the speeches.

In Albanian language we do have even the diaspora dialects (here include only the early Albanian dialects spoken by the Arbëresh, Albanian detached from their territories before Ottoman conquest). The condition of these dialects is more or less like this: they have inherited and inherit a common base that identifies them with Albanian people and development towards general Albanian is slower defined as those dialects are threatened every day by the danger of extinction. Of course, we all know that the speeches or dialects will disappear and new dialects will arise, but within a later documented Albanian and all the problems still unsolved, especially in the field of Albanian history (branch of the Indo-European family but documented too late, c. $15 \mathrm{AD}$ ), the values these dialects have, we must anticipate this risk. As Berruto say, "Different languages and cultures even those minority ones should be preserved and protected and not to push them towards extinction." (Berruto 1994)

Another dialect is the dialect of immigrants. Here is the way to see all the advantages of teaching Italian to Albanian immigrants, examining all internal linguistic factors, as well as taking into consideration external factors and psychological and socio-cultural factors that influence this process. An important factor in this regard is the example of Italian language learning as a communicating need of individuals, to be integrated into host communities. But we can't overlook the disadvantages that such a process leads to the cognitive aspect of language, where the first language (the language family) passes at a disadvantage; also can not overlook all the potential problems that may arise with the violation rate standard in both languages (Albanian and Italian).

In Albanian language we also have some other dialect spoken by ethnic Albanian lands subject to the situation of languages in contact as the dialect of Macedonian Albanians, Kosovo and Montenegro. The situation of languages in contact, especially in the context of possible interference in Albanian of slavish words have already been examined by researchers of these areas. But I think that will be of great interest the study of interference in the Albanian dialects by which the Albanian is in daily contact.

Albanian language recognizes internal displacement, as is the case of the Chameria Dialect. Residents underwent Cham ethnic cleansing in 1944 and moved to Albania's state lands in the form of a disheveled diaspora throughout Albania. Less or more the situation of this population is clearly defined by this statement: "The Albanians are moving freely in our land, with them, ideas, traditions, words. For many reasons, it is broken the linguistic enclave concept and the territory as a geographical concept serves no more for the definition of the dialect, which under the pressure of global society, is entering into a sociolect relationship with standard language and all language. "(Rrokaj 2010)

In all of the above dialects is clearly distinguishable the features of two variants or types of speech, the traditional version, which show stable storage elements of the old system and the new version, which reflects the broader transformations and changes of the system under macro system pressure(Shkurtaj 1998). But, although apparently the two sides of language development process in Cham environment, as elsewhere in Albania, are preservation (conservation) and restoration (renewal) of the dialect in the direction of standardization and globalization flattening, would add that, in this dialect is prominently displayed a third process which is as important as that of the presence of the first two. In a conventional way we called it "an Inter-process (interaction)", which plays the role of a liaison between the archaic Dialect and moderate Dialect. Evidently this kind of process occurs in Cham's middle generation who maintains the largest balance. His role here resemble that of a communication "channel" (corridor) between two generations (Troplini 2012).

After all these descriptions can't deny such occurrences worth in Sociolinguistics as: linguistic diversity, linguistic 
prejudices in speaking etc. Consequently, can't be denied the linguistic deficit that is inevitably caused to speakers thanks to the inequality gap created by factors diversity and the consequences of these factors. Therefore rests of this deficit are all the dialects of the above.

Thus, for an analysis of emigrants speech in this regard come to help not only the pre socio-pedagogical Bernstein's or Labov's studies, in Italy first ideas in this direction belong to the 70s, specifically Tuglio de Mauro. Another Italian researcher Don Milan calls the immigrants "desert", because according to him they are victims of a linguistic deficit that prevents the possibility of taking an active part in social and political life of the community (Melone \& Poggialli 2005).

From concrete data, is proved that the degree of difficulty of a child in emigration, a child displaced by a social community to another even within the country, is inevitable. In this way, like it or not we pass to another topic, to the factor socio-economic class, after evacuations in most cases are made from a poorer to a richer place (excluding the Cham case). But we also fully agree that in all cases, life has proven that the children of emigrant workers, displaced children from less desirable areas in the most privileged areas, have had a good performance in school regardless of their linguistic deficit, or social deficit, economic class (which language is related), and not only, but this deficit does not reduce the performance in school, at work, in life, to the extent that it becomes a limiting factor. Of course, individuals who are talking, pay a great tribute to overcome this kind of difficulty compared to the rest of the privileged ones. We are talking about the inequality gap, although it is always an attainable gap.

However, we cannot say that Bernstein's theses are irrelevant. A genuinely (socio) linguistic deficit by Brenstein's descriptions, which among other things has been quite pronounced in the past and continues to exist, is that among the so-called civic layer (Albanian citizenship) and rural strata (peasants) (initially distinguished from Shkurtaj Academician), which we intend to treat in another moment.

After all this we say that the role of standard Albanian, Italian, Greek and any relevant language of a host country is such that unifies language and flatten linguistic differences in the behavior of any individual if that native speakers, native or guest in a certain location. More than anywhere, standard's success is unquestionably observed in whole educational institutions of the state.

The question arises: is it enough for Albanian society?

Globalization primarily affects areas that are closer to the policy, such as the economy, public relations and external relations, all communication system written and oral and, in this broader context, the process undoubtedly affects interlinguistic relationships which (...) tend to follow the path of multiple interchange (Shkurtaj 2009).

In terms of today's contacts with the Albanian and its recent developments under the flow of communication, the model of "successful speech" sometimes contradicts the norm. Within the Albanian in the flow of communication in our Albanian society is noted deliberately that is created a kind of compelling bilingualism by society, which creates a deficit in linguistic behavior of individuals that among others, is also due to prejudices among speakers.

This refers to a type of inequality that Hudson calls "subjective inequality" (...) F simply said "XXXX", people who speak thus are of type (T) type people (T) are entertaining and $F$ is so entertaining (Hudson 2002: 232). Within this assessment linguistic scholars problem arises in this way: (...) the language itself may be subject to evaluation (...) Let us assume a society that recognizes a social stereotype S, which assesses negatively, for example, people see as "crass" S members. It is understood that the S-characteristic behavior will attract the same assessment, for example, if members of S's smoking a pipe, is also a common behavior and crass. Linking the language is clear: people think that the way of speaking to members of S's is common. (...) This estimate is based on the evaluation of speakers and not based on forms of discourse itself.

In such situations, language development plays an important role in improving language policies. So, the standard language should have unifying value not only in educational institutions. Linguistic norms should flatten any disparity in teaching communication and control all registers of speech. So, as said Shkurtaj is not enough simply having a standard, but we must have a developed standard (Shkurtaj 2009).

Linguistic deficit begins with the distinction between written language and spoken language. Albanian suffered strokes after changing systems and besides colloquial language was hit badly the written one. Speech patterns are created through written language so official language (Konica according Jorgaqi 2007: 14), but on the other hand, practical experience has shown that there is even the reverse: Wrong speech models are often reflected in the written language. A typical example of this, although permitted (from the beginnings of language itself) is loan. By borrowing we displace the focus from the speech to language systems. Loan has to do with mixing systems themselves, because a unit "is borrowed" from one language to be a unit of another language. So cannot deny the fact that an isolated Albanian under a dictatorship, after borders opening felt the need to foreign languages (Islamaj 2010), but, despite this fact it wasn't prepared for such a large influx of foreign words. Individual speaker wasn't merely a carrier of linguistic deficit, but 
deliberately in him was early created a noted deficit in culture and mentality.

In this way, for various quite common reasons, we opened indiscriminately the path for unnecessary words. Victim of this situation became state institutions to which models were borrowed "copy-paste" documents; different bad translated school texts full of unnecessary foreign words, where the pitch was the English words, even texts literally translated. Crucial role in the spread of this disaster played for a long time Albanian media.

Everything described caused a big language deficit in society, school, etc. In the open media linguists began to hum Renaissance ideas to clean Albanian language and the famous phrase from Çabej, cleaning the language from the foreign meat is a scientific task, also national, became the subject of discussion in various scientific conferences, seminars, TV programs etc.

In this context, often, due to a lower performance in school was just incomprehensible terminology for foreign students. Of course we can also talk about other types of terminology that are caused by other factors as incomprehensible terminology relevant to the field that is related to the teachers and students level, or what Hudson has called one of the possible aspects of linguistic inequality: "academic" language vocabulary that is related with the lexicon and the structures used by teachers in the teaching and the fact that how much are the children able to understand them. Large cultural and social deficits caused serious deficits in education.

These types of deficits became more apparent after 90s, but it is a phenomenon which has existed even before these years. Although the dictatorial communist state shout for equality, the right law again was totally false. One of the most striking phenomena of the Albanian society was that of persecution. Although in most cases the persecuted children had a great performance as most of these families striked on knowledge and culture (this meant that they were generally the first anywhere), this fact deliberately influence on teaching performance. Students (children of persecuted) were put in front of two ways: either consciously neglected the study, or to devote themselves passionately to him despite the circumstances, being very successful even though the fate of the right to study depended totally by the dictatorial state. These unfortunates had the opportunity regardless of age, to fulfill their ambitions after changing systems. The persecuted became unwitting carrier of a compelling deficit by the system.

Religion is another important variable in Sociolinguistics. Scapegoat of the dictatorial system became even the civil right of the faith in God. Many words of the religious culture remained in limbo during the dictatorship. Passive vocabulary fate had also come to the surface after all these years. Linguistic diversity by faith, in Albanian society is in its infancy (although there existed long ago) Today, on these individual speakers of this social group has begun to sharply observed a kind of linguistic deficit which is likely to increase in the future. This deficit is caused mainly due to the use of different terminology. In speech are observed distinct forms of greeting, use of special terminology in everyday life by respective religions (most pronounced is this phenomenon on festive occasions, according to various religious rites, etc.). Solidarity with the observed social group in setting personal names mainly of their religion, rooted phenomenon of early recovery and a slightly different nowadays (Troplini 2013). Getting outside literary rate in such cases is exceeded. An important role for closing the gap that is created especially to children, play educational institutions even if they would be subject to private schools with predominantly religious shaft.

At the conclusion of this paper we can say that the"developed" standard should bear in mind all the above mentioned factors of linguistic diversity, as well as all those factors which give rise to diversity, cognitive aspects of language, mentalities and cultures, situations and certain contexts, that speakers are inevitably exposed from day to day. So we have always been of the opinion that the language policy cannot simply mean a standard language, but the standardization of individual behavior in general which includes in itself all possible links between linguistic structures and social structures.

\section{References}

Klein, G., "La sociolinguistica": Orientamenti della ricerca negli Stati Uniti, in Gran Bretagna e nella Repubblica federale tedesca Firenze : La nuova Italia, 1977.

Shkurtaj Gj. Albanian sociolinguistics, SHBLU, Tirana 2009.

Shkurtaj GJ. Sociolinguistics, Tirana 2003.

Shkurtaj Gj. Layers and linguistic innovation in Lezha city, in "Studies in Philology" 2, p. 75-93, 1984.

Shkurtaj Gj. Observations on dialectal and literary lexical layers in the dialect of Lezha, in "St. Fil. "3, p. 155-163, 1981

Troplini, E. The role of standards in unifying language and leveling of differences in linguistic behavior of individual international conference, Skopje, October 2011.

Troplini, E. Problematic "language and social layer" in Albania, press conference held at the International Faculty of Education, University "Alexander Moses", Durres 2010 
Troplini, E. Albanian language learning in our schools. (Some problems of language planning), held press conference organized at the Faculty of History and Philology, Tirana 2010 ..... etc..

Troplini, E. The theory of linguistic deficit under today's Albanian contacts, press held in the XXIX seminar of Language, Literature and Albanian Culture, in Pristina, 2010.

Troplini, E. The role of standards in unifying language and leveling of differences in linguistic behavior of individual,International conference, Skopje, October 2011.

Troplini, E.: Cham dialect of yesterday and today, Ph.D., Tirana 2012

Troplini, E.: Theory of linguistic deficit within the clash of mentalities and cultures. (Research sociolinguistic the personal names of Albanian), Romania (Baia Mare), 2013

Gjinari, J. Today's relations with the literary language dialects, SF, 1985.

Hudson, A. R. Sociolinguistics (first edition in Albanian), Tirana 2002.

Berruto, G. Sociolinguistica, Bologna, 1994 (reprint of 1974-es)

Rrokaj SH: All Albanians should speak Albanian standards, the newspaper "Panorama", date 15/12/2010

Shkurtaj, Gj.: Some of the occurrence of Kurbin Dialect in light of sociolinguistics, SF, 1998.

Shkurtaj, Gj. Sociolinguistics, SHBLU, Tirana 2003.

Melone, E. \& Poggialli, Sperimentazione di testi a "scrittura controllata" in Unità didattiche di storia, dissertation, under the direction of Roberta Grassi, 2004/2005.

De Mauro, T., "La crisi della pedagogia linguistica tradizionale". Scuola e società, 1976

Jorgaqi Kristina: Faik Konica, Linguist Thoughts, p. 14, Ombra GVG-Studies-2007.

Islamaj, Sh.: Prishtina Press Workshop 2010

Internet: http www.comunicazionidimassa.net/ 